\title{
A Critical Survey of Predictive Mathematical Models for Migration from Packaging
}

\author{
MARIA F. POÇAS, ${ }^{1}$ JORGE C. OLIVEIRA, ${ }^{2}$ FERNANDA A. R. OLIVEIRA, ${ }^{2}$ \\ and TIMOTHY HOGG ${ }^{1}$
}

\author{
${ }^{1}$ Packaging Department, Biotechnology College, Portuguese Catholic University, Rua Dr. António Bernardino de Almeida, \\ 4200-072 Porto, Portugal \\ ${ }^{2}$ Process and Chemical Engineering Department, University College Cork, Cork, Ireland
}

Keywords plastic packaging, Fick's law, diffusion coefficient, partition coefficient, probabilistic models

\begin{abstract}
The migration of chemicals from food contact materials into foods is an important issue in food safety. The assessment of materials compliance with regulations includes migration monitoring for many monomers and additives. However, it is recognized that predictive mathematical modelling can be used in many cases, to avoid or to reduce the effort on migration experiments. This article reviews the approaches followed to apply mathematical models to migration, particularly the models used, the approaches to estimate model parameters, and the systems used to experimentally validate the models. Conclusions on the issues requiring further research are drawn.
\end{abstract}

\section{Introduction}

Mathematical models which describe physical processes of practical interest are of great use as replacement for, or auxiliaries to, the experimental study of the actual process. Thus, models describing the mass transfer of additives and other contaminants from packaging materials to foods represent invaluable tools for industry professionals and regulators alike. Such models can at least partially, substitute expensive and timeconsuming migration experiments. The models may have as objective the assessment of compliance with regulatory specific migration limits, or to describe the concentration change of migrating species with time, in either the polymer or in the food, for reasons that depend on the species under study. A considerable amount of work has been devoted to modelling the transfer of substances used in the production or conversion of the materials, such as monomers and particularly additives like antioxidants and stabilizers. More recently the use of mathematical models has been employed to corroborate the safety and effectiveness of a virgin polymer layer (often called functional barrier) in avoiding any possible food contamination from recycled plastics used

Address correspondence to Maria F. Poças, Packaging Department, Biotechnology College - Portuguese Catholic University, Rua Dr. António Bernardino de Almeida, Porto 4200-072, Portugal Tel: +351 225 580085; Fax: 351225 580111: E-mail: mfpocas@esb.ucp.pt in laminated or coextruded structures (Feigenbaum et al., 2005; Dole et al., 2006a; Dole et al., 2006b). Models have also been used to describe the release of active substances, such as antimicrobials (Sadikoglu et al., 2006).

The advantages of mathematical modelling in the prediction of migration have long been recognized by researchers and this has also been acknowledged by policy makers and current legislation includes the use of a deterministic migration model as a tool for enforcement authorities and in consumer exposure estimation (Petersen et al., 2005; Franz, 2005).

The objective of this work is to present a systematic review of the information available in the literature regarding the mathematical modelling of migration of substances from plastic packaging into foods or food simulants, focusing on the situations leading to different mathematical expressions of the model, on the determination of model parameters and on the model systems studied.

\section{Type of Models}

Mathematical models may follow a number of approaches as: deterministic, empirical, stochastic, or probabilistic, including uncertainty and variability. The deterministic models are based on a theory describing a physico-chemical phenomenon. This 
approach considers that variables assume a single and constant value leading to a single output value of migration. A considerable amount of work has been devoted to the development and assessment of deterministic models based on Fick's law of diffusion (Table 1).

Empirical models are purely mathematical, i.e., they are based on equations that yield a good fit with experimental observations regardless of any physical meaning of the constants of the model or understanding of the underlying mechanisms. The Weibull model, for example, is a model of an empirical nature that has been used to describe different processes in food processing, quality, and safety. Apparently, the empirical approach has not been used to model migration from packaging. One case can be mentioned of a model describing the quantity migrated as a function of temperature and time, developed using a response surface approach (Fauconier et al., 2001).

Stochastic models are represented by functions of probability distributions. Instead of predicting the migration level observed after a given storage time, a stochastic model yields the probability of a certain value of migration occurring in a certain food/packaging combination for a given time and temperature, or whose migration values are most probable to occur (Petersen, 2000). Stochastic models may be based on distributions such as the normal distribution. A model to predict the probability distribution of the diffusion coefficient from the molecular mass of the migrant, assuming a normal distribution, was presented by Helmroth $\left(2002^{\mathrm{c}}\right)$.

Probabilistic models are those that take into account the variability and uncertainty that the values of the variables can assume and the probability of their occurrence. This includes mixed effects models which combine deterministic models with variability in the model parameters. The model output is, thus, a distribution of values, the constants of the model also having a distribution of values rather then a single one. Variability is a property of nature; it cannot be reduced through further study or additional measurements. In packaging/food combinations, the observed values of migration are subjected to variability due to heterogeneity in the composition and structure of both the packaging system and food product. At the laboratory scale variability is also unavoidable, even when standard procedures are used. Uncertainty also entraps ignorance or lack of knowledge, which in many cases can be reduced through further study or expert information. In the case of food packaging, lack of knowledge concerning the distribution chain (e.g. temperature), time of contact, and other non-systematic error sources would contribute to uncertainty in the values of the variables. Probabilistic modelling approaches are based on techniques which propagate information about the variability and/or uncertainty through the model. Numerical simulation methods, based on simulated random sampling are commonly used and the most well-known of these methods is the Monte Carlo simulation. Another numerical simulation method employed in this type of approach is the Latin Hypercube Sampling (Cullen and Frey, 1998).

\section{Applications of specific medelling approaches}

Most of the reported studies in this area employ a deterministic approach, based on the assumption that the mass transfer from the packaging material into the food is a diffusional process that can be described by Fick's law (1). Given the dimensions and formats of most packages, one-dimensional diffusion from a infinite slab may be assumed.

$\frac{\partial C_{A}^{P}}{\partial t}=D_{A}^{P} \frac{\partial^{2} C_{A}^{P}}{\partial x^{2}}$

where $C_{A}^{P}$ represents the concentration of the migrating species $A$ in the packaging material $\mathrm{P}, t$ represents the time, $x$ the linear dimension of migration, and $D_{A}^{P}$ is the diffusivity of $A$ in the packaging material.

Figures 1 to 4 show typical profiles of concentration of substance $A$ migrating from a packaging material $P$ into a food $F$, in different situations corresponding to different boundary conditions and assumptions. For each case the solution of equation (1), and eventual simplifications, are also presented.

In terms of initial conditions, it is considered that the initial concentration of the migrant in the food is zero and that the migrant is initially homogeneously distributed in the packaging material matrix. The validity of this will depend on the production process and package construction, but in many cases for single layer packages it is a good approximation. Ageing effects of packages stored for long periods of time can lead to considerable loss of migrants, particularly those of low molecular weight near the interface. In such cases, the migrant is no longer homogeneously distributed in the material as assumed in the theory and resulting in an overestimation in modelling.

In the absence of a chemical reaction or evaporation, the general mass balance equation gives: the initial amount of $A$ present in the packaging materials is equal to the sum of the total amount that migrates into the food after time $t$, plus the amount remaining in the packaging. This is valid at any instant and hence at equilibrium. Therefore,

$M_{A}^{P}(0)=M_{A}^{P}(t)+M_{A}^{F}(t)$ or

$M_{A}^{P}(0)=M_{A}^{P}(\infty)+M_{A}^{F}(\infty)$

where $M_{A}^{i}(t)$ represents the mass of $A$ present in phase $i$ at time $t$.

At equilibrium, two constants may be defined, $K_{P}$ and $\alpha$ :

$$
K_{P}=\frac{C_{A}^{P}(\infty)}{C_{A}^{F}(\infty)} \quad \text { and }
$$

$\alpha=\frac{M_{A}^{F}(\infty)}{M_{A}^{P}(\infty)}=\frac{C_{A}^{F}(\infty) V^{F}}{C_{A}^{P}(\infty) V^{P}}=\frac{V^{F}}{K_{P} V^{P}}$ 


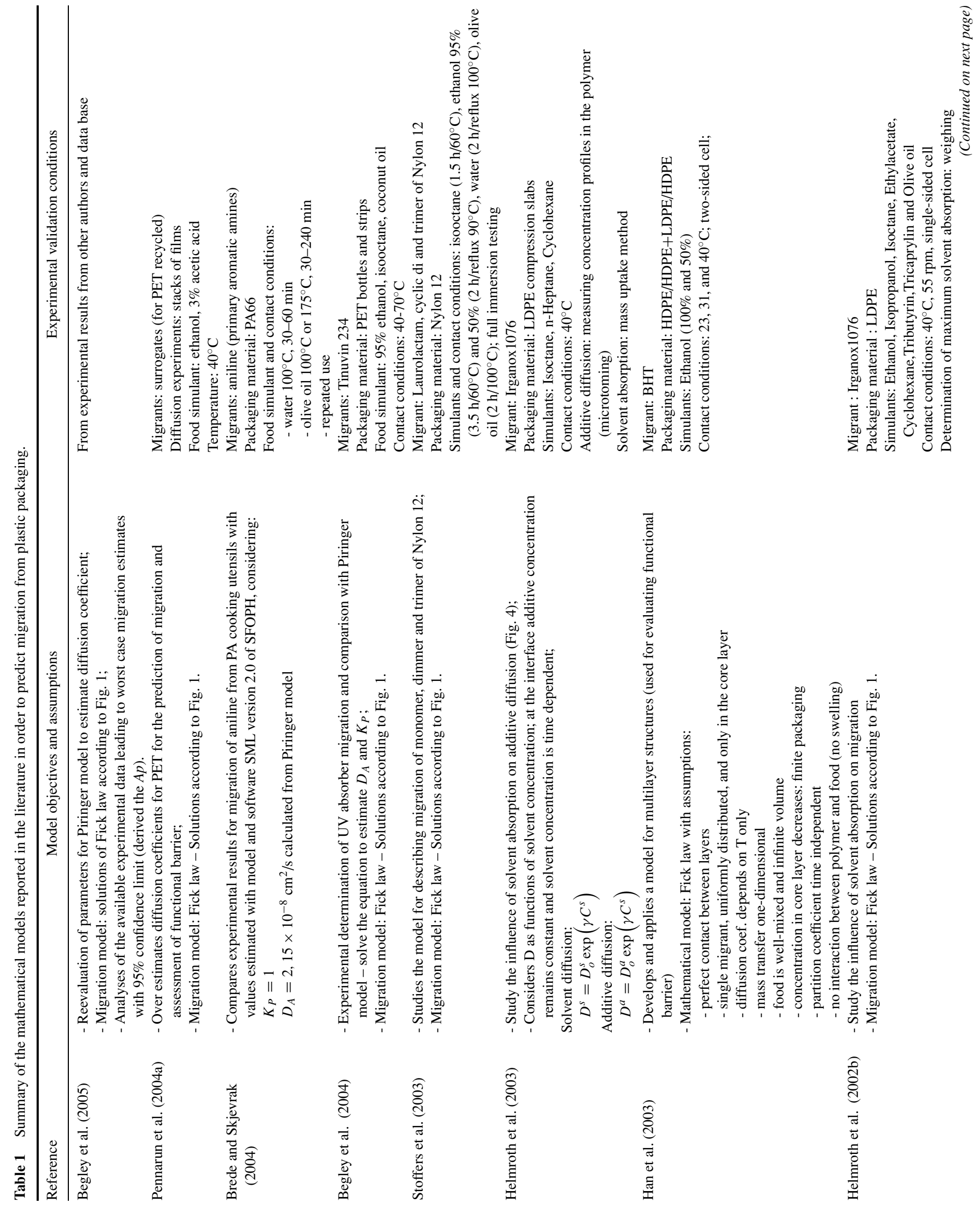




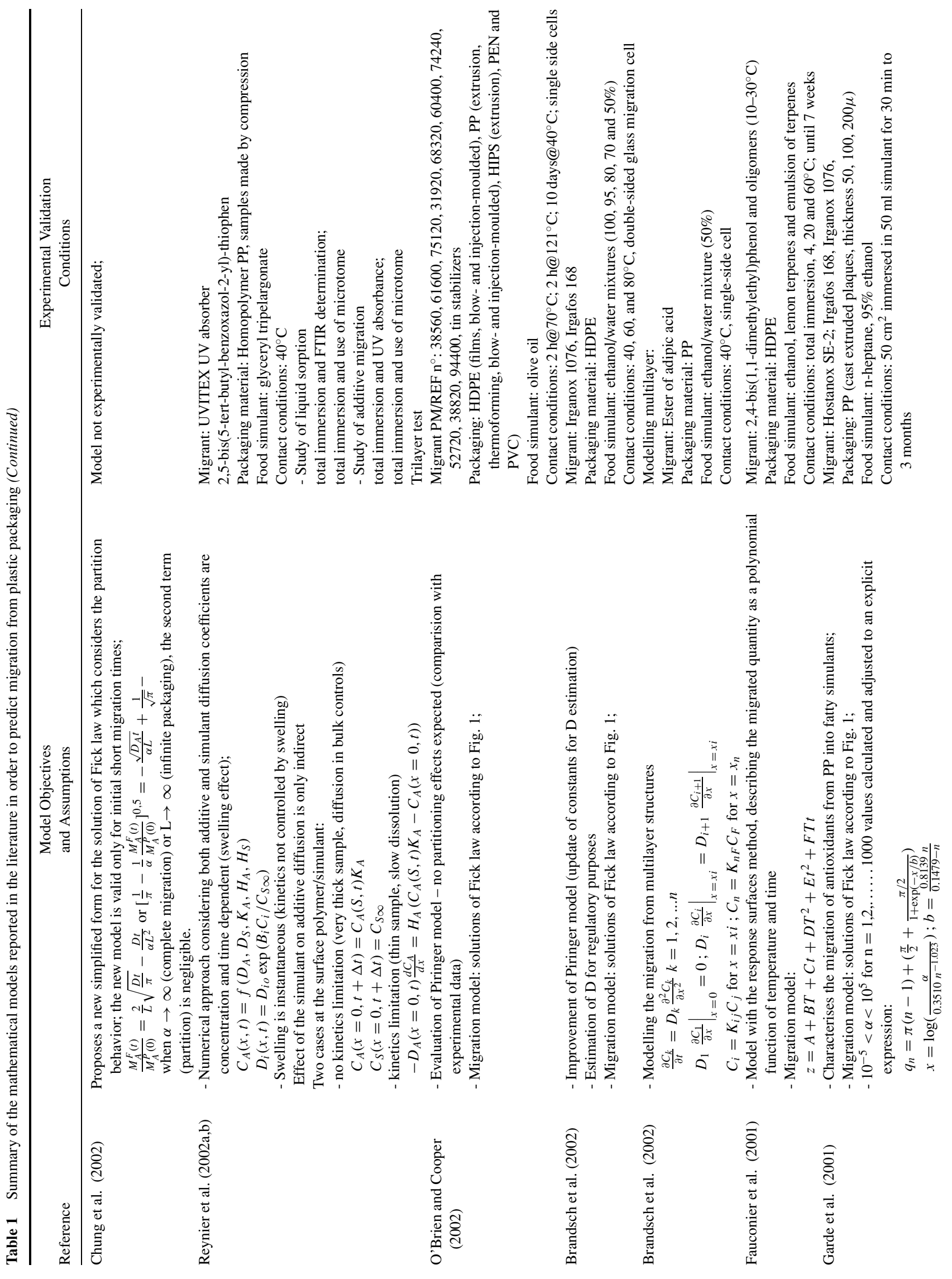



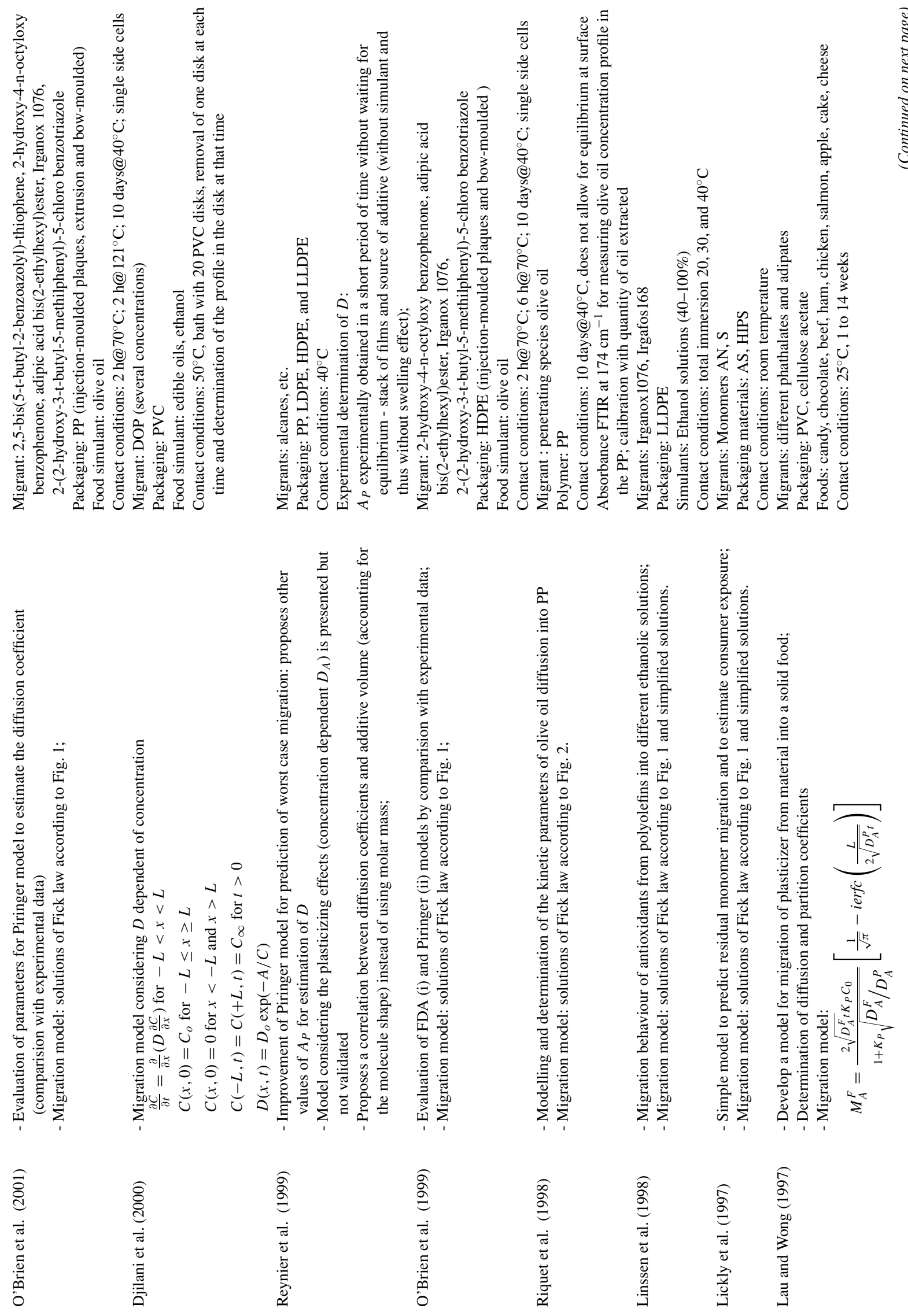


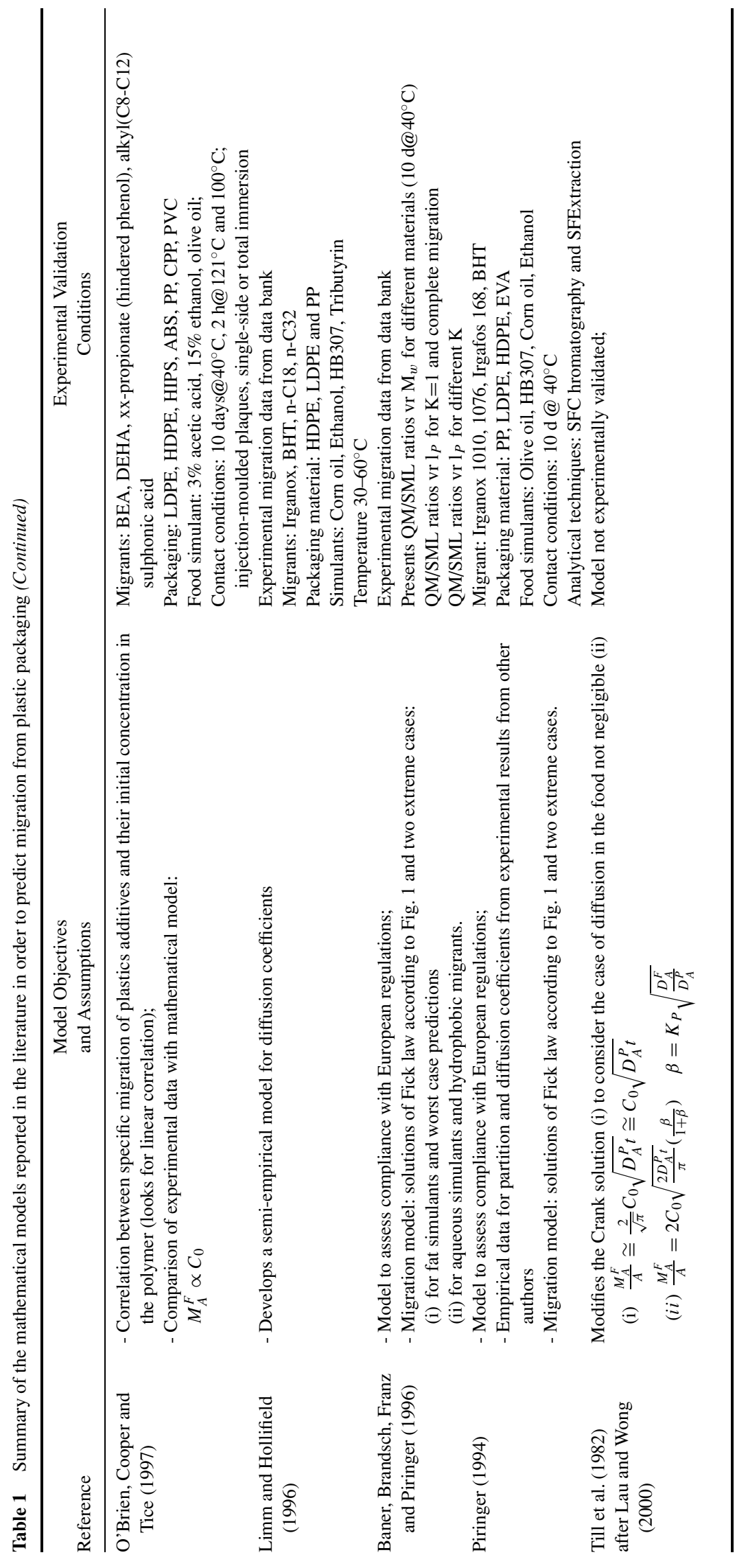




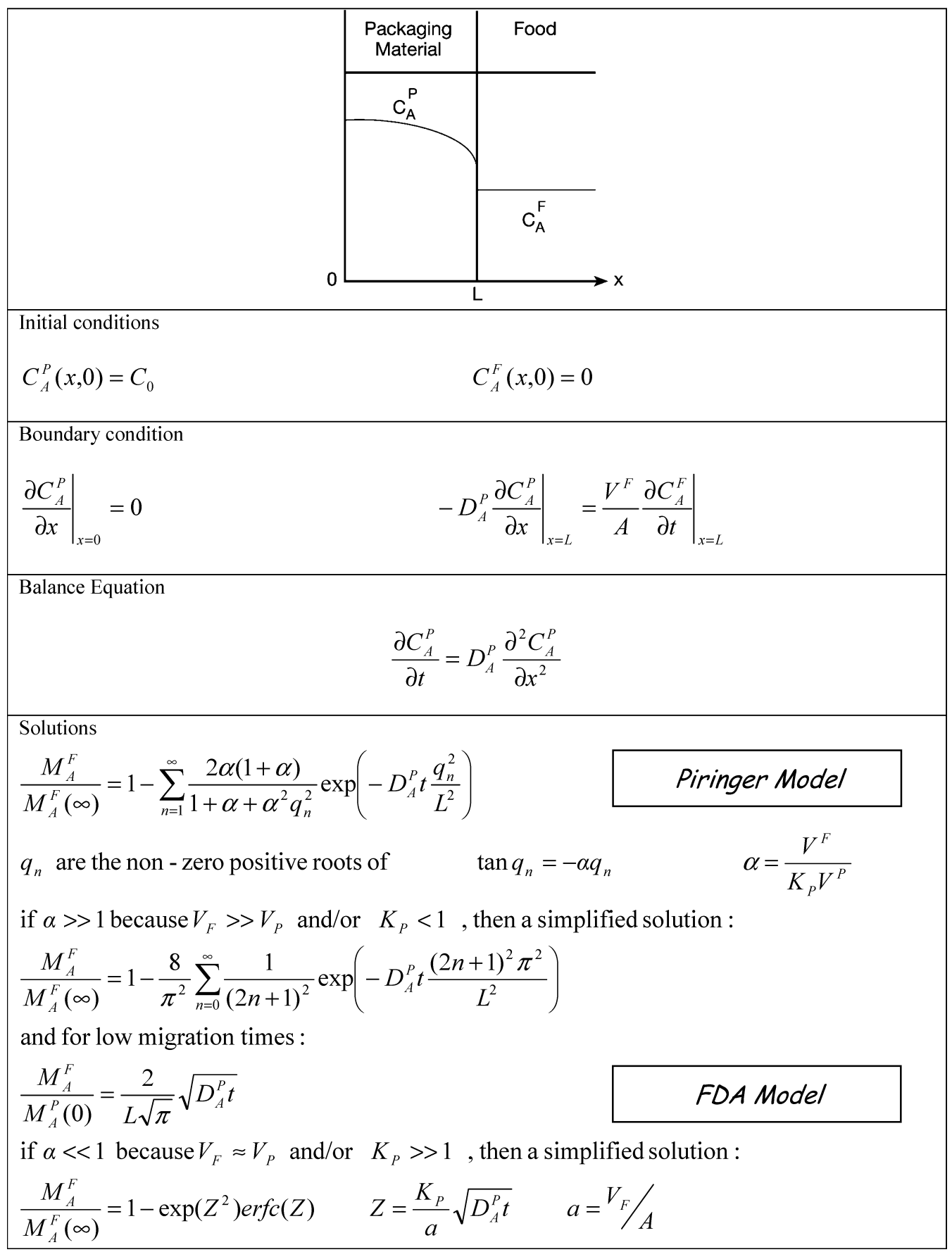

Figure 1 Migration controlled by diffusion in the packaging material

$K_{P}$ represents the partition coefficient of $A$ in the system packaging material/food, which can be assumed as constant for low concentrations.

The boundary conditions establish that there is no transfer at the outer surface of the packaging material which is valid to assume if the migrant is of low volatility. The boundary condition at the surface of the packaging material in contact with the food depends on which mass transfer resistances at interface must be considered. Figure 1 represents the case of negligible mass transfer resistance on the side of the food, which is the case for a well-mixed food or a Bi number greater than 100 . The migration process is controlled by the diffusion of the migrant through the packaging material and the migrant is well distributed in the food. Most of the work developed (Table 1) considers the system packaging/food as described by boundaries leading to analytical solutions as shown in Fig. 1 (Pennarun et al., 2004a; Begley et al., 2004; Stoffers et al., 2003; Garde et al., 2001).

Figure 2 represents the case where the mass transfer resistance on the side of the food is not negligible, but can be 


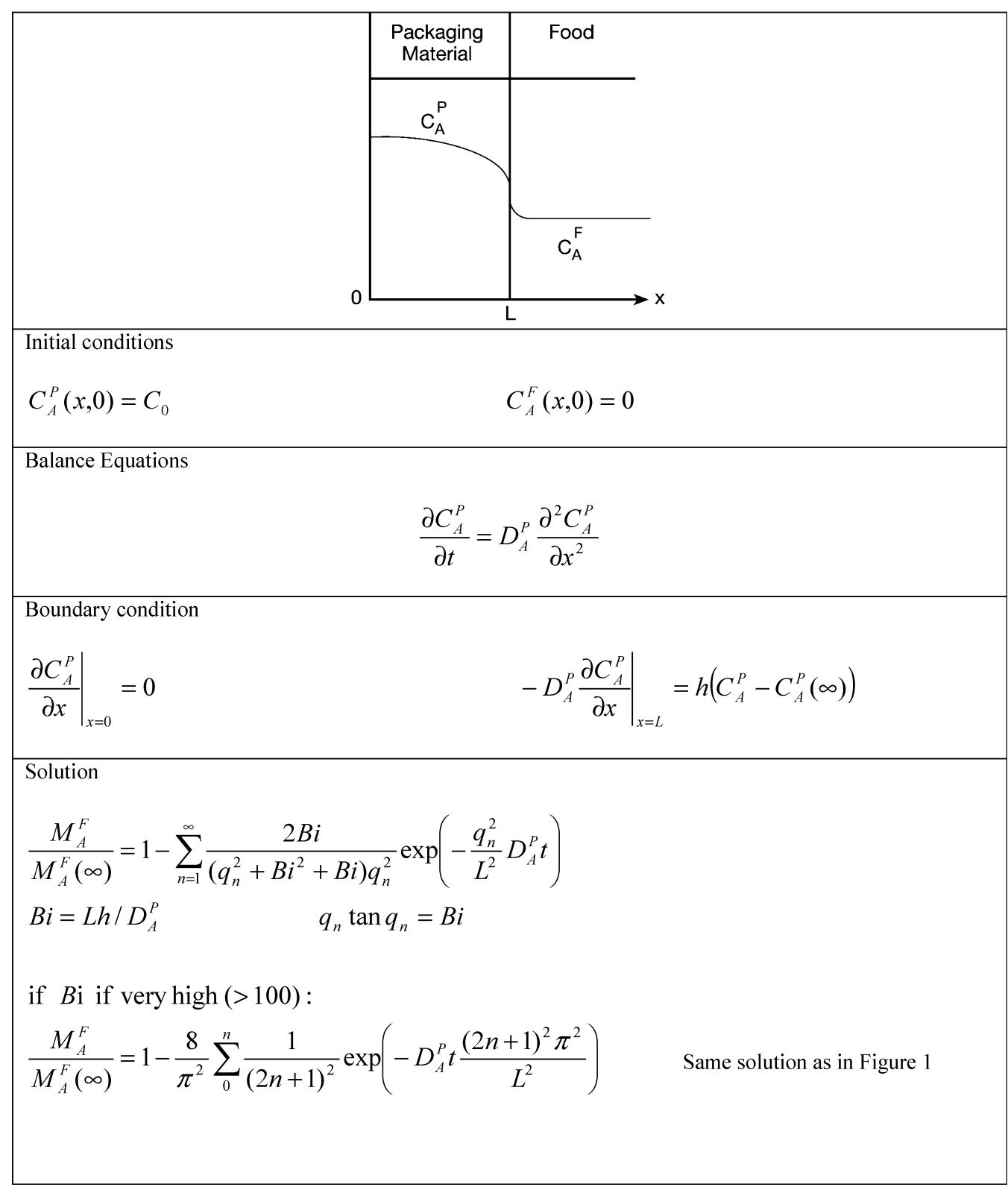

Figure 2 Migration considering diffusion in the polymer and convection/boundary layer resistance in the food

approximated by a convective process, with a gradient in the boundary layer, and the convective mass transfer coefficient $(h)$ is not infinite. The effect of $h$ was discussed in Verganud, 1998; Reynier, 2002a,b; and Vitrac and Hayert, 2005; but very few values are available in the literature for food packaging applications.

In many practical cases the food can be assumed to be stirred, not controlling the diffusion of the migrant, particularly in the case of liquid foods or simulants. For solid or semi-solid foods, however, this assumption is unlikely to be valid and the transfer of migrants will be influenced also by the diffusion in the food itself, and a diffusion coefficient in the food $D_{A}^{F}$ must also be accounted for, although much less effort has been dedicated to this case (Lau and Wong, 1997 and 2000). This situation is illustrated in Fig. 3.
The behavior at the packaging/food interface also depends on whether the partition effects must be considered. Depending on the $K_{P}$ value and the packaging geometry, at equilibrium the migrant A may be transferred totally into the food or only partially. In some practical cases, the ratio of food volume/packaging volume is high $(>10)$ and if $K_{P}<1$, as in hydrophobic migrants migrating into fatty foods, then $\alpha>>1$ and it can be assumed that the whole amount of $A$ migrates; if $K_{P}>1$, as in aqueous foods, then only part of the initial amount present at the packaging material migrates into the food. These two "border" cases correspond to the two extremes of polarity of food simulants defined in the EU regulations for migration tests for many additives (Fig. 4): $K_{P}<1$ for non-polar fat simulants, like olive oil and HB 307 and $K_{P}>>1$ for polar aqueous simulants (Piringer, 


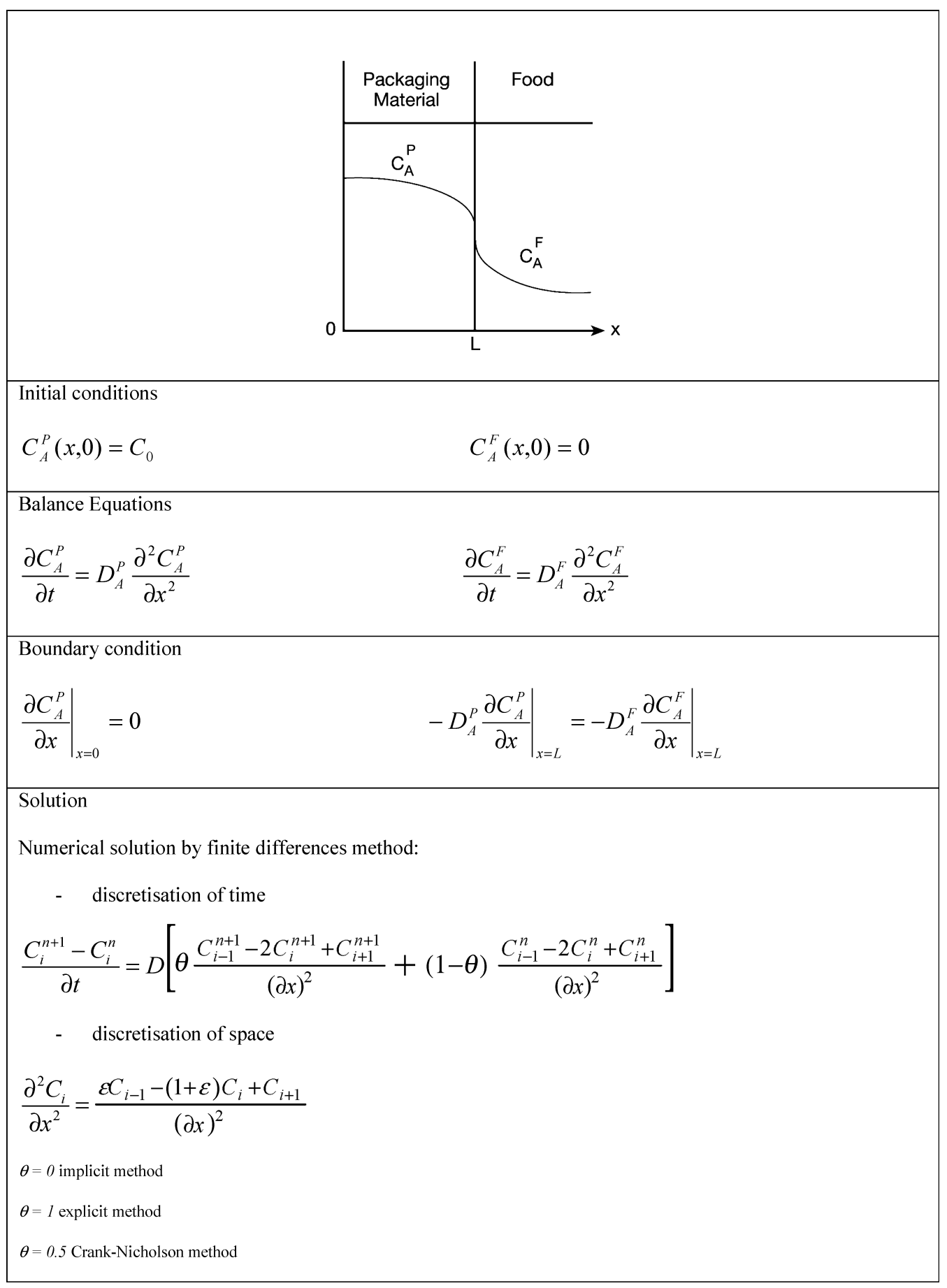

Figure 3 Migration considering diffusion in both the packaging material and food

1994). In these extreme cases, the simplified solutions of equation (1), as shown in Fig. 1, are often used (Linssen et al., 1998; Lickly et al., 1997; Baner, Brandsch, Franz, and Piringer, 1996).

In Figs. 1, 2, and 3 it is considered that the food does not interact with the packaging material, i.e., it does not penetrate into the material. Therefore, the diffusion coefficient of the migrant $A$ in the packaging material $D_{A}^{P}$, is considered to be constant, independent of time, location, and species concentration. This may be true for low concentrations of the migrant which happens in most cases. An exception is made for systems with additives at concentrations higher than $10 \%$, for example plasticizers in PVC (Djilani et al., 2000).

If swelling of the packaging material occurs, that is penetration of $F$ into $P$, a mixed phase $(P / F)$ or a swelling layer located between the still unchanged material and the food is formed (Fig. 4). The thickness of this layer increases with time, 


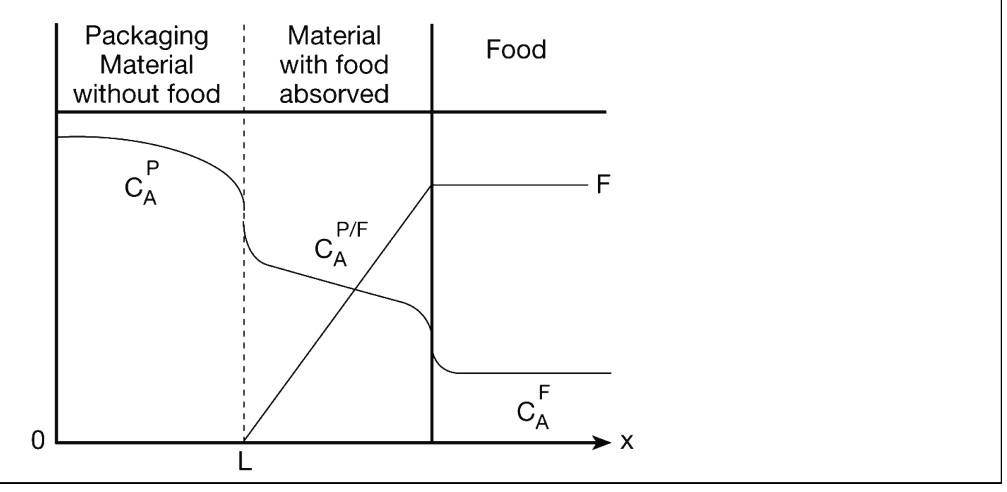

Figure 4 Migration considering interaction between the food simulant and the packaging material

and as a rule, the diffusivity of the migrant in this mixed phase is greater than in the unchanged material (Figge, 1980). Consequently, $A$ migrates faster from a partially swollen material than from a material which, due to its properties, does not absorb the food $-D_{A}$ becomes dependent of time and on the relative distance to the food/polymer interface (Helmroth et al., 2003; Reynier et al., 2001). Riquet et al. (1998) determined the mass transfer coefficients $(D$ and $h$ ) for the penetration of olive oil into PP.

The simplicity or complexity of the model solutions depend on the objectives behind the model and thus on the accuracy required. If the model objective is to assess compliance with specific migration limits, estimates such as the maximum amount migrated within a certain storage time or the amount migrated at equilibrium are the answers required. If the objective requires the estimation of the migration process during the whole period or with more precision, then solutions more complex, usually found numerically, are required. However, considering the computing power available today, the simplifications assumed in the past to allow easier calculations are no longer necessary.

\section{Determination of Model Coefcients}

Migration prediction, according to models based on Fick's Law, requires data for at least two fundamental constants: the diffusion coefficient $\left(D_{A}^{P}\right)$ and the partition coefficient $\left(K_{P}\right)$. The first is a measure of "how fast" the migrant travels in the matrix and the second describes the relation between the concentration in the packaging material and in the food, at equilibrium, or "how much" migrant is transferred to the food.

Diffusion in a polymer is influenced by several factors (Limm and Hollifield, 1996): (i) related to the polymer and to the manufacturing process, such as molecular weight distribution, density, cristallinity, orientation, solubility parameters; (ii) migrant factors, such as molecular size and shape; (iii) polymermigrant interaction factors, such as plasticization effect; and (iv) temperature factors: polymer glass transitions and melting temperature.
The diffusion coefficient may be determined from migration values, i.e. following the concentration of the migrant in the food simulant with time, or directly, measuring the concentration profile in the polymer at various times (Rosca et al., 2001). The former approach takes into account the effects at the interface material/simulant but the solid/solid tests avoid the potential plasticizing and partitioning effects (Reynier et al., 1999; Pennarun, 2004a,b). These determinations can be accomplished by using a stack of migrant-free plastic films in contact with a migrant source, or using a single sheet with higher thickness and then using a microtome to obtain sections of the polymer sheet, where individual values of the concentration are obtained (Helmroth et al., 2002a). Although less demanding in terms of equipment, the stack method has the major drawback that the transfer of the migrant between layers influences the results.

The determination of model coefficients can be as time consuming as the actual migration experiments. For this reason, an empirical relationship between the diffusion coefficient and the molecular weight of the migrant and the temperature was established for LDPE, HDPE, and PP based in published results (Piringer, 1994; Baner, 1996) and later improved and extended to other plastics (Brandsch et al., 2002):

$$
D_{A}^{P}=10^{4} \exp \left(A_{P}-C_{1} M_{w}^{2 / 3}+C_{2} M_{w}-C_{3} / T\right) \mathrm{cm}^{2} / \mathrm{s}
$$

where $\mathrm{T}$ is the temperature in ${ }^{\circ} \mathrm{K}, C_{1}, C_{2}$, and $C_{3}$ are constants and $A_{P}$ is a polymer dependent constant, according to:

$$
A_{P}=A_{P}^{\prime}-\frac{\tau}{T}
$$

Equation 6 is applicable to migrants of molecular weight $M_{w}$ in a wide range from 100-2000, and represents an Arreheniuslike relationship, with the parameter $\tau$ and the constant $C_{3}$, both with the dimension of temperature, contributing to the diffusion activation energy. The parameter $C_{1}$ results from a correlation between the molar volumes and masses of the series of n-alkanes. $C_{2}$ accounts for the decreasing impact of molecular weight on the diffusion coefficient at increasing molecular 
Table 2 Constants for estimation of diffusion coefficients in plastics (Equations 6 and 7).

\begin{tabular}{lccc}
\hline Polymer & $A_{P}^{\prime}$ & $\tau$ & $\mathrm{T},{ }^{\circ} \mathrm{C}$ \\
\hline LDPE/LLDPE & 11.5 & 0 & $<90$ \\
HDPE & 14.5 & 1577 & $<100$ \\
PP (homo and random) & 13.1 & 1577 & $<120$ \\
PP (rubber) & 11.5 & 0 & $<100$ \\
PS & 0.0 & 0 & $<70$ \\
HIPS & 1.0 & 0 & $<70$ \\
PET & 6.0 & 1577 & $<175$ \\
PEN & 5.0 & 1577 & $<175$ \\
PA (6,6) & 2.0 & 0 & $<100$ \\
\hline Constants & $C_{1}$ & $C_{2}$ & $C_{3}$ \\
\cline { 2 - 4 } & 0.135 & 0.003 & 10454 \\
\hline
\end{tabular}

weights (Piringer, 2000; Brandsch et al., 2002). Parameter $A_{P}$ was derived from published diffusion coefficients from many different sources (Mercea, 2000), considering an upper limit defined statistically to account for scattering of data. This also provides a safety margin to avoid underestimation of the diffusion coefficient which may lead to values of migration lower than those experimentally determined and a consequent acceptance of a non-compliant food contact material. Given this conservative approach, equation 6 provides upper values of $D_{A}^{P}$ for a given molecular weight and temperature, which are used to assess compliance with regulation limits in Europe. Table 2 summarizes the constants for equations 6 and 7 for the major polymers used in food packaging (Begley et al., 2005).

A considerable amount of published work has been devoted to the evaluation of migration estimates using this model (O'Brien et al., 1999, 2001, 2002) and to improving model parameters (Reynier et al., 1999; Brandsch et al., 2002). The Practical Guide presents a list of substances from the Directive 2002/72 for plastic materials with specific migration limits, for which migration modelling is applicable as a tool for compliance verification.

Alternatives to the estimation of $D_{A}^{P}$ based on the molecular weight of the migrant using this Arrhenius-like relationship, have been proposed. In one approach the diffusion coefficients were correlated with the weighted, fractionated volume of the migrant molecule (Reynier et al., 2001) and in another Vitrac and his co-workers proposed a relationship with the Van der Waals volume, the gyration radius, and a shape parameter (Vitrac, Lézervant, and Feigenbaum, 2006).

The estimation of diffusion coefficients in foods rather than simulants, for a set of migrants, was the focus of the FoodMigrosure European project (QLK1-CT2002-2390). By measuring the concentration profiles of the migrant in the food at two temperatures, an average $E_{a}$ was determined and applied for the calculation of the specific constant $A_{F}$ (Brandsch et al., 2006a,b):

$A_{F}=\ln D_{A}^{F}+\frac{E_{a}}{R T}$

In a two-phase food/packaging material system, migrant transfer from one phase to the other proceeds until the thermodynamic equilibrium between the phases is reached. The partition coefficient is defined as the ratio of migrant concentration in the packaging material to its equilibrium concentration in the food or simulant phase (4). The partition depends on the specific properties of the migrant, of the food, and of the material. Relevant properties include the chemical structure and molecular size of the migrant, the $\mathrm{pH}$ and fat content of the food, phase, the nature of the packaging material, and the storage temperature (Tehrany and Desobry, 2004). As the migrants will be present in low amounts in the food, it is a fair assumption to a linear equilibrium relationship, that is, a constant partition coefficient. Apparently, less effort has been devoted to the determination or estimation of partition coefficients of safety related migrants from packaging materials when compared to the studies related to the absorption of aroma and flavor compounds of the food by the material.

In the absence of specific data, the partition coefficient is commonly taken as $K_{P}=1$, meaning that the migrant is very soluble in the food phase (Begley et al., 2005). This assumption leads to the highest migration values at equilibrium and it is commonly used in models employed in the assessment of compliance with migration limits established by legislation (Piringer, 1994; Baner et al., 1996; O'Brien et al., 2001, 2002; Helmroth et al., $2002^{\mathrm{c}}$ ). If the migration limits are not exceeded when employing this conservative assumption, the safety is assured and no experimental work is required (EC, 2003). To get more precise estimates the use of experimental values of $K_{P}$ is recommended. Partition coefficients can be determined experimentally by conducting migration experiments until or close to equilibrium. It should be noted that if relatively thick materials are used, equilibrium may not be achieved in a reasonable time frame. Brandsch and his co-workers (Brandsch et al., 2006 ${ }^{\mathrm{a}, \mathrm{b}}$ ) proposed a loglinear relationship between the partition coefficient of migrants between the plastic and the food $\left(K_{P}\right)$ and the partition coefficient of the migrants in an octanol/water system $\left(K_{o / w}\right)$, the latter being the standard quantity to characterize the hydrophobicity/hidrophilicity of a molecule (Tehrany and Desobry, 2004). The relationships were established as "upper-level safety limits" for specific food groups such as liquids, milk products, meat products, cheese products, margarine/mayonnaise, etc.

$\log \left(K_{P}\right)=C_{4} \log \left(K_{o / w}\right)-C_{5}$

Most of the experiments that aim to determine the diffusion and partition coefficients are carried out in tailor-made specimens rather than in real packages. A comparison between migration values from sheets to migration values from packages show that, usually, migration from moulded packages is lower than migration from sheets, due to edge effects (Figge and Freytag, 1984). However, polymer conversion techniques, such as thermoforming or blow-moulding, do not seem to have a significant influence on the migration values (O'Brien et al., 2002). 
Polymer-Food Systems Studied

Table 1 presents a compilation of studies related to mathematical modelling applied to migration of components from packaging. It briefly presents the objectives of the work, the model assumptions, and the experimental conditions for model validation, particularly the migrant species and the packaging materials in question.

Polyolefins (LDPE, LLDPE, HDPE, and PP) are the group of packaging plastics most often used in migration studies for mathematical modelling. Elements of this group of plastics are very often the layers actually in contact with food. The quantity of available migration and diffusion data is much smaller for PET, PEN, PS, HIPS, and PA than for polyolefins. The inherent low diffusivity in these non-polyolefins has led to numerous experiments showing non-detectable results for migration (Begley et al., 2005). Diffusion takes place through the amorphous phase of the polymers. Therefore, the crystallinity and glass transition temperature (and its relation to the temperature of use) greatly influence the diffusion rate. Little data is available for polymers that are glassy at their temperature of use. In such cases the experimental duration is much longer, due to lower values of diffusivity.

Polyolefins are non-polar materials (Fig. 5) and will be in a rubbery state at their temperature of use $\left(\mathrm{Tg} \sim-20^{\circ} \mathrm{C}\right)$. When in contact with non-polar simulants, for many additives which are hydrophobic, polyolefins yield low partition coefficients resulting in high values of migration of the additives at equilibrium. For these reasons, polyolefins are often used in migration experiments for modelling purposes, since they allow for faster and more sensitive results. In most cases, the migration of antioxidants is the subject under study (Piringer, 1994; Lissen, 1998; O’Brien et al., 1997, 1999, 2001; Garde, 2001).

Polystyrene (PS) is commonly used for yogurt cups and other dairy products, confectionery, etc. Despite having a $\mathrm{Tg}$ of $90^{\circ} \mathrm{C}$, it is totally amorphous at temperatures of interest for food packaging applications. Styrenic polymers have also been studied, particularly for the migration of the monomer styrene (Choi et al., 2005; Lickly et al., 1997) and additives (O'Brien et al., 1997).

PVC has seen its application in food packaging greatly reduced, although it still finds a major application in medical

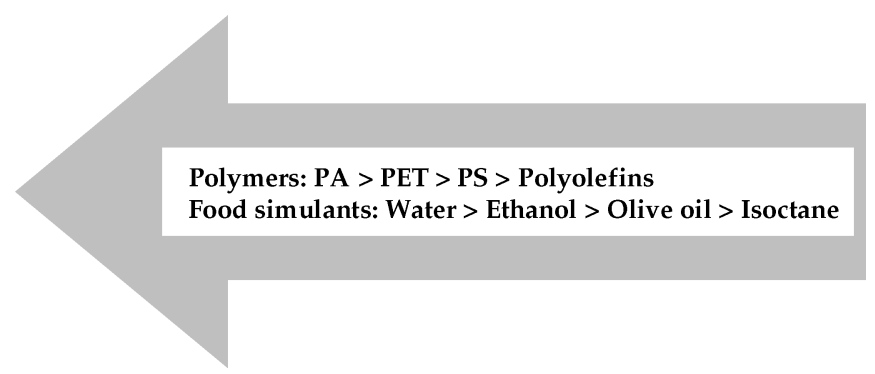

Figure 5 Relative polarity of polymers and food simulants devices where a direct contact also occurs and thus the migration of the VC monomer and particularly of plasticizers is a concern (Djilani et al., 2000).

The family of polyamide (PA) is applied very often as packaging materials or utensils intended for repeated use at elevated temperatures and relatively short periods of contact time. PA has been studied for the migration of monomers like caprolactam from PA6 (Bradley et al., 2004), cyclic di- and trimerlaurolactam from PA12 (Stoffers, et al., 2003), and primary aromatic amines, a product of a reaction of isocyanates residues from PA66 with water (Brede and Skjevrak, 2004). There are less data available for estimation of diffusion coefficients and these are strongly affected by water absorbed by the material. Therefore, the migration values into water or aqueous simulants are higher than migration values into olive oil.

PET shows very low levels of global migration (Castle et al., 2004). Due to the low diffusivity of most migrants in PET, the determination of diffusion coefficients in PET requires long term experiments. Although there are a number of studies on migration from PET of substances such as terephthalic acid, ethylene glycol, acetaldehyde and others, there are few studies on the determination of specific mass transfer characteristics (Begley et al., 2004). In most applications, very low amounts of additives are added to PET. UV stabilizers are, probably, the most important from a safety point of view (Monteiro et al., 1999; Begley et al., 2004). The diffusion properties of PET, which are glassy at room temperature, are expected to be strongly influenced by the liquid in contact (as the kinetics is limited by swelling), as well as by the nature and the concentration of the migrants (Pennarun, 2004 ${ }^{\mathrm{a}}$ ). Begley et al. (2004) found interaction between ethanol solutions and PET (both polar) causing diffusion to be faster than into isooctane, a non-polar simulant (Fig. 5). Pennarun et al. $\left(2004^{\mathrm{b}}\right)$ showed that the $D$ values in PET are more sensitive to the molecular weight of diffusing species than in LDPE. Most of the more recently reported migration modelling studies for PET, are related to the capability of a virgin layer of this polymer to provide an efficient barrier to migration of potential contaminants present in outer recycled layers (Han et al. 2003; Pennarum et al., 2004 ${ }^{\mathrm{a}}$ ).

In studies for model development, the migrating substance should be selected taking into consideration the stability under migration/extraction conditions, the properties such as polarity, volatility, molecular weight, etc. and the analytical methods for quantification in either the polymer or in the food simulant. In the literature reviewed, the migrants often used are commercial additives such as antioxidants and stabilizers (Irganox, $\mathrm{Ir}$ gafos, BHT, etc.). Irgafos 168 is a recommended test substance to experimentally establish the diffusion behavior of polymers according to the EU legislation (Practical Guide). Although this compound is always accompanied by its oxidation product, Irgafos $1680 x$, the reproducible mass balance of the two substances and the analytical ease of detection, allow the simultaneous determination of the sum of the parent and the degradation products. 
Table 3 Characteristics of software available for migration simulation

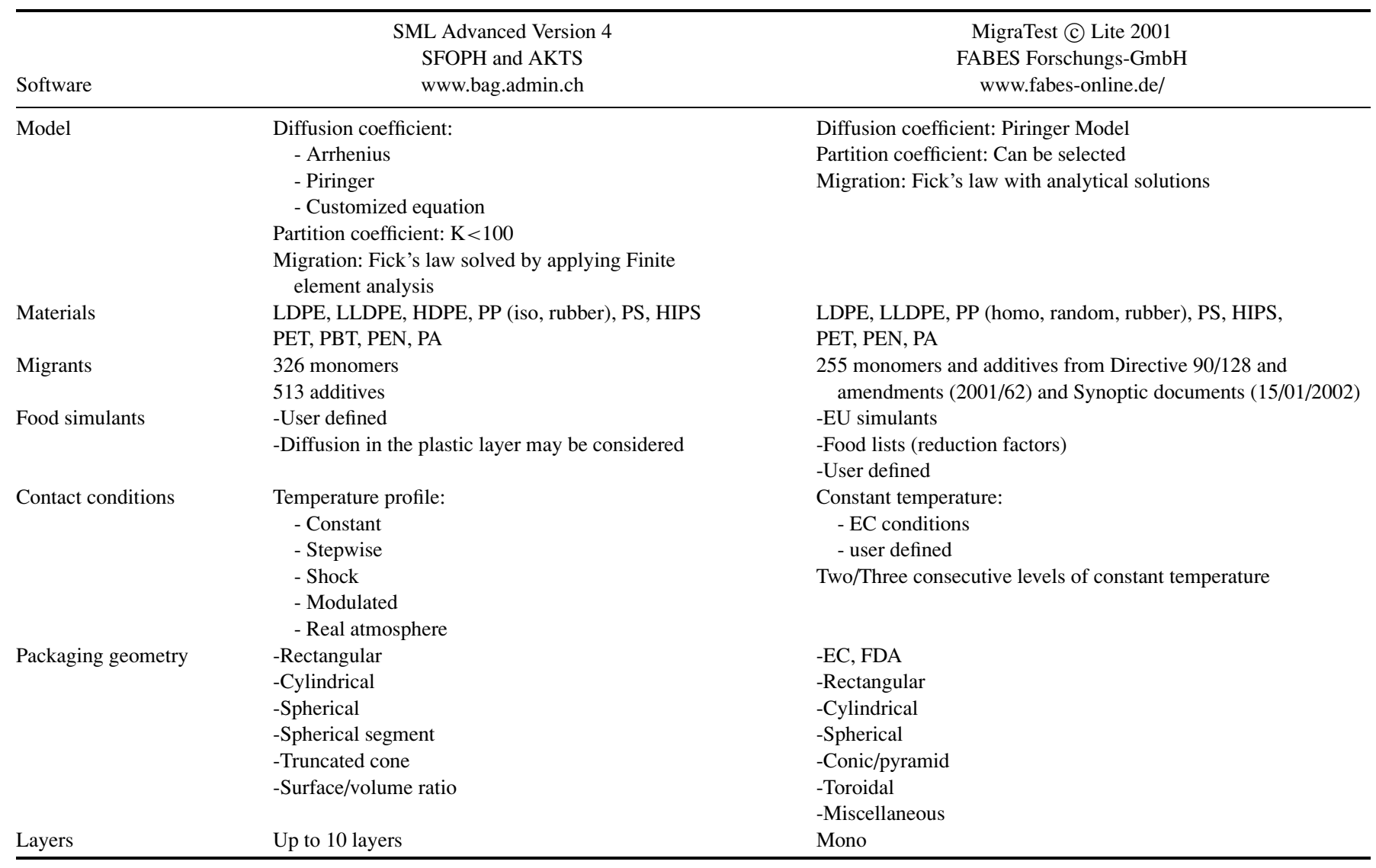

\section{Computer Programs}

To perform model calculations for the prediction of the migration values and to handle data of migrants and packaging systems, a number of software applications have been made available. These programs are intended as a tool by laboratories and industries in assessing the compliance with regulatory limits of specific migration.

Table 3 presents the characteristics of the two, more commonly cited, user-friendly programs:

(1) Migratest Lite 2001 (Revised April 2003) was developed by Fabes GmbH: based on Piringer model (Brandsch et al., 2002; Piringer, 1994; Baner et al., 1996); estimates the diffusion coefficients by applying equation (6). It is based on European Union regulations (although FDA standard packaging may be selected) and it includes a data-base on the substances legislated by the EU: including migration limits, common concentrations of use, diffusion coefficients, and partition coefficients; it considers two limit situations $\mathrm{K}=$ 1 or $\mathrm{K}=1000$, if a predefined simulant is selected.

(2) AKTS-SML Software is available as a freeware for monolayer materials and as a licensed version for materials with up to 10 layers. It employs Finite Element Analysis (FEA) to solve the model equations (Roduit et al., 2005). Calculation of the diffusive process is based on Fick's law. It considers the Arrhenius equation and the last version of the Piringer model with refined $A_{p}$ constant for the approximation of the diffusion coefficients. Diffusion and concentration distribution in the package layer can be computed for both migrant leaving and food components entering the packaging. The program $A K T S-S M L$ is a joint development of the Swiss Federal Office of Public Health (SFOPH) and the company Advanced Kinetics and Technology Solutions AG (AKTS AG).

INRA has available a freeware SMEWISE (Simulation of Migration Experiments with Swelling Effect) available at http://www.inra.fr/Internet/Produits/securite-emballage/pagefr. html\#haut and according to the model described in the literature (Reynier et al., 2002). The software (in operative system DOS) is for numerical resolution of equations of the model that considers the diffusion coefficients of both additive and simulant dependent of time and concentration; this research group has also the freeware MULTITEMP for mass transfer during polymer conversion and MULTIWISE for multilayer materials (Dole et al., 2006 ${ }^{\mathrm{b}}$ ).

\section{Conclusions}

Most of the work developed concerns deterministic modelling, as shown in Table 1, and the models were developed to 
assess compliance with regulatory limits. In this case, model coefficients are estimated, or approximated, with safe margins (and worst case assumptions) instead of precise determinations. The absolute worst-case migration model, verifies what would be the final concentration of the migrant in the food or simulant if all migrants are transferred from the polymer. If the specific migration limit is not exceeded, then no further model refinement or experimental determination is required.

The mathematical models presented in Table 1 are almost all based on Crank's solutions of Fick Law. Two major cases may be pointed out: the "FDA model" based on system assumptions leading to a simple solution valid for low migration times, and the "Piringer model," a more elaborate solution (Fig. 1). O'Brien et al. (1999) compared these two solutions for the migration of a number of additives from HDPE into olive oil, and found that the FDA model was more accurate in most situations, but underestimated the results more frequently.

In Europe, the Piringer model has been evaluated and a comparison of model predicted values with experimental results has shown that, in $95 \%$ of the cases, the model overestimates the migration values (O'Brien et al., 1999, 2001, 2002; Begley et al., 2005). This means that the model can be used to support and verify compliance with the regulations, ensuring a margin for consumer safety. However, the need for models to be able to produce estimations close to the real values, reducing the overestimations (Begley et al., 2005) and reducing the risk of rejecting safe packaging systems has been recognized.

Deterministic models do not give information on the variability or the uncertainty in the migration values. Stochastic and probabilistic approaches have proved to be excellent tools in a number of research areas and are receiving increased interest in packaging research dealing with migration. For regulatory evaluation, the uncertainty of overall migration is set to be $2 \mathrm{mg} / \mathrm{dm}^{2}$ or $12 \mathrm{mg} / \mathrm{kg}$. These values were based on ring trials carried out within the CEN working group. However, for migration of specific compounds the variability of the diffusion and partition coefficients, for example, is not known. Therefore, probabilistic approaches in this field still require considerable research effort.

\section{Nomenclature}

A

$A_{P}, A_{P}^{\prime}, \tau$

$A_{F}$

$\mathrm{Bi}$

$C_{A}^{I}$

$C_{1}, C_{2}, \mathrm{C}_{3}$

$C_{4}, C_{5}$

$D_{A}^{P}$

$D_{A}^{F}$
Contact surface area normal to direction of diffusion

Polymer constants for diffusion coefficient estimation

Food constant for diffusion coefficient estimation Biot number

Concentration of A in I phase

Constants for diffusion coefficient estimation

Constants for partition coefficient estimation

Diffusion coefficient of $A$ in the packaging material $P$

Diffusion coefficient of $A$ in the food $\mathrm{F}$

$\begin{array}{ll}D_{A}^{P / F} & \text { Diffusion coefficient of } A \text { in the P/F phase } \\ E_{a} & \text { Energy of activation } \\ h & \text { Coefficient of convective mass transfer } \\ \text { HDPE } & \text { High density polyethylene } \\ K_{P} & \text { Partition coefficient between } P \text { and } F \\ K_{o / w} & \text { Partition coefficient in the system octanol/water } \\ \text { LDPE } & \text { Low density polyethylene } \\ \text { LLDPE } & \text { Linear Low density polyethylene } \\ M_{A}^{I} & \text { Mass of A in I phase } \\ M_{w} & \text { Molecular weight } \\ \text { PVC } & \text { Polyvinyl Chloride } \\ \text { PET } & \text { Polyethylene terephthalate } \\ \text { PP } & \text { Polypropylene } \\ \text { PA } & \text { Polyamide } \\ (\text { HI)PS } & \text { (High impact) Polystyrene } \\ \text { Phase } P & \text { Unchanged packaging material in which the mi- } \\ & \text { grant is present at } t=0 \\ \text { Phase } P / F & \text { Packaging material P swollen by the packaged } \\ & \text { product } F \\ \text { Phase } F & \text { Packaged product } \\ t & \text { Time } \\ T & \text { Temperature } \\ T_{g} & \text { Glass transition temperature } \\ V & \text { Volume of phase I } \\ x & \text { Space coordinate in the direction of diffusion } \\ & \end{array}$

\section{References}

Begley, T. (1997). Methods and approaches used by FDA to evaluate the safety of food packaging materials. Food Additives and Contaminants 14:6-7.

Begley, T., Castle, L., Feigenbaum, A., Franz, R., Hinrichs, K., Lickly, T., Mercea, P., Milana, M., O’Brien, A., Rebre, S., Rijk, R., and Piringer, O. (2005). Evaluation of migration models that might be used in support of regulations for food-contact plastics. Food Additives and Contaminants 22(1):73-90.

Baner, A., Brandsch, J., Franz, R., and Piringer, O. (1996). The application of a predictive migration model for evaluation compliance of plastic materials with european food regulations. Food Additives and Contaminants 13(15):587601.

Bradley, E. L., Speck, D. R., Read, W. A., and Castle, L. (2004). Method of test and survey of caprolactam migration into foods packaged in nylon-6. Food Additives and Contaminants 21(12):1179-1185

Brandsch, J., Mercea, P., Rüter, M., Tosa, V., and Piringer, O. (2002). Migration modelling as a tool for quality assurance of food packaging. Food Additives and Contaminants 19:Supl., 29-41.

Brandsch, R., Mercea, P., Zülch, A., Piringer, O., and Tosa, V. (2006a). Determination of physical-chemical parameters of food. Proceedings of Closing Conference of FoodMigrosure Project, Baveno, Italy, 27-28 September.

Brandsch, R., Mercea, P., Zülch, A., Piringer, O., and Tosa, V. (2006b). Migration model for foods. Proceedings of Closing Conference of FoodMigrosure Project, Baveno, Italy, 27-28 September.

Brede, C., and Skjevrak, I. (2004). Migration of aniline from polyamide cooking utensils into food simulants. Food Additives and Contaminants. 21(11):11151124

Castle, L., Macarthur, R., Mead, E. M., and Read, W. A. (2004). Measurement uncertainty associated with overall migration testing. Food Additives and Contaminants. 21(3):256-264.

Choi, J., Jitsunari, F., Asakawa, F., and Sun Lee, D. (2005). Migration of styrene monomer, dimers and trimers from polystyrene to food simulants. Food Additives and Contaminants 22(7):693-699. 
Chung, D., Papadakis, S. E., and Yam, K. L. (2002). Simple models for assessing migration from food-packaging films. Food Additives and Contaminants 19(6):611-617.

Cullen, A. C., and Frey, H. C. (1999). Probabilistic techniques in exposure assessment: a handbook for dealing with variability and uncertainty in models and inputs. Society of Ris Analysis. Plenum Press, New York.

Djilani, S-E., Bouchami, T., Krid, F., Boudiaf, N., and Messadi, D. (2000). Comparaison des simulations chimique et mathematique de la migration do DOP a partir de disques de PVC plastifie plonges dans des huiles comestibles. European Polymer Journal 36:1981-1987.

Dole, P., Feigenbaum, A., La Cruz, C., Pastorelli, S., Paseiro, P., Hankemeier, T., Voulzatis, Y., Aucejo, S., Saillard, P., and Papaspyrides, C. (2006a). Typical diffusion behaviour in packaging polymers - application to functional barriers. Food Additives and Contaminants 23(2):202-211

Dole, P., Voulzatis, Y., Vitrac, O., Reynier, A., Hankemeier, T., Aucejo, S., and Feigenbaum, A. (2006b). Modelling of migration from multi-layers and functional barriers: estimation of parameters. Food Additives and Contaminants 23(10):1038-1052.

European Commission. (2003). Practical Guide for Users of European Directives. EU-DG SANCO.

Fauconnier, M. L., Panhaleux, V., Vanzeveren, E., Marlier, M. M., and Wathelet, J. P. (2001). Modelling migration from high-density polyethylene containers into concentrated solutions used as food flavourings. Food Additives and Contaminants 18(11): 1040-1045.

Feigenbaum, A., Dole, P., Aucejo, S., Dainelli, D., La Cruz, C., Hankemeier, T., N'gono, Y., Papaspyrides, C., Paseiro, P., Pastorelli, S., Pavlidou, S., Pennarun, P. Y., Saillard, P., Vidal, L., Vitrac, O., and Voulzatis, Y. (2005). Functional barriers: properties and evaluation. Food Additives and Contaminants 22(10):956-967.

Figge, K. (1980). Migration of components from plastics - packing materials into packed goods - test methods and diffusion models. Prog. Polym. Sci. 6:187-252.

Figge, K., and Freytag, W. (1984). Additive migration from various plastics with different processing or properties into Test Fat HB307. Food Additives and Contaminants. 1(4).

Franz, R. (2005). Migration modelling from food-contact plastics into foodstuffs as a new tool for consumer exposure estimation. Food Additives and Contaminants 22(10):920-937.

Garde, J. A., Catalá, R., Gavara, R., and Hernandez, R. J. (2001). Characterizing the migration of Antioxidants from polypropylene into fatty food simulants. Food Additives and Contaminants. 18(8):750-762.

Han, J-K, Selke, S., Downes, T. W., and Harte, B. R. (2003). Application of a computer model to evaluate the ability of plastics to act as functional barriers. Packaging Technology and Science. 16:107-118.

Helmroth, I. E., Bekhuis, H. A. M., Linssen, J. P. H., and Dekker, M. (2002a) Direct measurement of additive migration from low-density polyethylene as a function of space and time. Journal of Applied Polymer Science 86:31853190.

Helmroth, I. E., Dekker, M., and Hankemeier, T. (2002b). Influence of solvent absorption on the migration of irganox 1076 from LDPE. Food Additives and Contaminants 19(2):176-183

Helmroth, I. E., Rijk, R., Dekker, M., and Jongen, W. (2002c). Predictive modelling of migration from packaging materials into food products for regulatory purposes. Trends in Food Science and Technology. 13:102109.

Helmroth, I. E., Dekker, M., and Hankemeier. (2003). Additive diffusion from LDPE slabs into contacting solvents as a function of solvent absorption. Journal of Applied Polymer Science 90:1609-1617.

Lau, O-W., and Wong, S-K. (1997). Mathematical model for the migration of plasticizers from food contact materials into solid food. Analytica Chimica Acta. 347:249-256.

Lau, O-W., and Wong, S-K. (2000). Contamination in food from packaging material. Journal of Chromatography A. 882:255-270.

Linssen, J. P. H., Reitsma, J. C.E., and Cozijnsen, J. L. (1998). Research note migration of antioxidants from polyolefins into ethanolic solutions. Packaging Technology and Science 11:241-245.
Lickly, T. D., Rainey, M. L., Burgert, L. C., Breder, C. V., and Borodinsky, L. (1997). Using a simple diffusion model to predict residual monomer migration - consideration and limitations. Food Additives and Contaminants 14(1):6574.

Limm, W., and Hollifield, H. C. (1996) Modelling of additive diffusion in polyolefins. Food Additives and Contaminants 13(8):949-967.

Mercea, P. (2000). Diffusion data for low molecular weight organic substances in polyethylenes. Ch. In Plastic Packaging Materials for Food. Ed. O. Piringer \& A. Baner. Wiley-VCH Verlag GmbH, 469-530.

Monteiro, M., Nerín, C., and Reyes, F. G. R. (1999). Migration of tinuvin P, a UV stabilizer, from PET Bottles, into fatty-foods simulants. Packaging Technology and Science 12:241-248.

O'Brien, A., and Cooper, I. (2002). Practical experience in the use of mathematical models to predict migration of additives from food-contact polymers Food Additives and Contaminants 19Supl.:63-72.

O'Brien, A., and Cooper, I. (2001). Polymer additive migration to foods - a direct comparison of experimental data and values calculated from migration models for polypropylene. Food Additives and Contaminants 18(4):343-355.

O'Brien, A., Goodson, A., and Cooper, I. (1999). polymer additive migration to foods - A direct comparison of experimental data and values calculated from migration models for high density polyethylene (HDPE). Food Additives and Contaminants 16(9):367-380.

O'Brien, A., Cooper, I., and Tice, P. A. (1997). Correlation of specific migration $\left(\mathrm{C}_{F}\right)$ of plastics additives with their initial concentration in the polymer $\left(\mathrm{C}_{\mathrm{P}}\right)$ Food Additives and Contaminants 14(6):705-719.

Pennarun, P. Y., Dole, P., and Feigenbaum A. (2004a). Overestimated diffusion coefficients for the prediction of worst case migration from PET: application to recycled PET and to functional barriers assessment. Packaging Technology and Science 17:307-320.

Pennarun, P. Y., Dole, P., and Feigenbaum A. (2004b). Functional barriers in pet recycled bottles. part i. determination of diffusion coefficients in bioriented PET with and without contact with food simulants. Journal of Applied Polymer Science. 92: 2845-2858.

Petersen, J. H., Trier, X. T., and Fabech, B. (2005). Mathematical modelling of migration: a suitable tool for the enforcement authorities? Food Additives and Contaminants 22(10):938-944.

Peterson, B. J.(2000). Probabilistic modelling: theory and practice. Food Additives and Contaminants 17:591-599.

Piringer, O. G. (1994). Evaluation of plastics for food packaging. Food Additives and Contaminants 11(2):221-230.

Piringer, O. (2000). Prediction of diffusion coefficients in gases, liquids, amorphous solids and plastic materials using an uniform model. Ch. In Plastic Packaging Materials for Food. Ed. O. Piringer \& A. Baner. Wiley-VCH Verlag GmbH, 159-181.

Reynier, S. A., Dole, P., and Feigenbaum, A. (2002). Integrated approach of migration prediction using numerical modelling associated to experimental determination of key parameters. Food Additives and Contaminants 19:Supl., $42-55$.

Reynier, S. A., Dole, P., and Feigenbaum, A. (2002). Migration of additives from polymers into food simulants: numerical solution of a mathematical model taking into account food and polymer interactions. Food Additives and Contaminants 19(1):89-102.

Reynier, S. A., Dole, P., and Feigenbaum, A. (2001). Diffusion coefficients of additives in polymer. i. correlation with geometric parameters. Journal of Applied Polymer Science 82:2422-2433.

Reynier, S. A., Dole, P., and Feigenbaum, A. (1999). Prediction of worst case migration: presentation of a rigorous methodology. Food Additives and Contaminants 16(4): 137-152.

Riquet, A. M., Wolf, N., Laoubi, S., Vergnaud, J. M., and Feigenbaum, A. (1998). Food and packaging interactions: determination of the kinetic parameters of olive oil diffusion in polypropylene using concentration profiles. Additives and Contaminants 15(6):690-700.

Roduit, B., Borgeat, C. H., Cavin, S., Fragnière, C., and Dudler, V. (2005). Application of finite element analysis (FEM) for the simulation of release of additives from multilayer polymeric packaging structures. Food Additives and Contaminants 22(10):945-955 
Rosca, D., El Kouali, M., and Vergnaud, J. M. (2001). Testing of a simple method for measuring the diffusivity of a chemical through polymers. Polymer Testing 20:563-568.

Sadikoglu, H., Sen, D., and Ozdemir, M. (2006). A mathematical model for potassium sorbate diffusion through whey protein films. Drying Technology 24:21-26.

Stoffers, N. H., Dekker, M., Linssen, J. P. H., Störmer, A., and Franz, R. (2003). Alternative fatty food simulants and diffusion kinetics of nylon 12 . Food Packaging 20(10):949-959.

Tehrany, E., and Desobry, S. (2004). Partition coefficients in food/packaging systems: a review. Food Additives and Contaminants 21:1186-1202.
Vergnaud, J. M. (1998). Problems encountered for food safety with polymer packages: chemical exchange, recycling. Advances in Colloid and Interface Science 78:267-297.

Vitrac, O., Mougharbel, A., and Feigenbaum, A. (2007). Interfacial mass transport properties which control the migration of packaging constituents into foodstuffs. Journal of Food Engineering 79(3):1048-1064.

Vitrac, O., Lézervant, J., and Feigenbaum, A. (2006). Decision trees as applied to the robust estimation of diffusion coefficients in polyolefins. Journal of Applied Polymer Science 101(4):2167-2186.

Vitrac, O., and Hayert, M. (2005). Risk assessment of migration from packaging materials into foods. AIChE Journal 51(4):1080-1095. 